\title{
KINETIC PROFILE OF THE ANTIOXIDANT ACTIVITY OF PROPOLIS EXTRACT: 2,2-DIPHENYL-1-PICRYLHYDRAZYL RADICAL BLEACHING
} ASSAY

\author{
Snježana Mirković ${ }^{1}$ \\ Katarina Rajković2* \\ Sanja Jeremić3 \\ Marijana Gavrilović ${ }^{2}$ \\ Ljiljana Tomić ${ }^{1}$ \\ Valentina Arsić Arsenijević ${ }^{4}$ \\ Boro Krstić 5 \\ ${ }^{1}$ Faculty of Pharmacy, University of Bijeljina, Bijeljina, Bosnia and Herzegovina \\ 2College of Applied Studies of Technics and Technology, Kruševac, Serbia \\ IInstitute of Molecular Genetics and Genetic Engineering, University of Belgrade, \\ Belgrade, Serbia \\ ${ }^{4}$ Institute of Microbiology and Immunology, Faculty of Medicine, University of \\ Belgrade, Serbia \\ ${ }^{5}$ Faculty of Agriculture, University of Bijeljina, Bijeljina, Bosnia and Herzegovina \\ *corresponding author: katar1970@yahoo.com \\ Received: 21 August 2017; accepted: 1 December 2017
}

Abstract

The objective of this paper was to assess the antiradical effectiveness of propolis extract (PE) based on 2.2-diphenyl-1-picrylhydrazyl radical (DPPH') bleaching assay kinetic profile. The kinetic profile of scavenging DPPH' for PE exhibited one kinetic period characterized by one kinetic constant. The second-order rate constant $\left(k_{2}\right)$ for the oxidation of PE by DPPH', determined for the first time in this study, was $0.17 \mathrm{dm}^{3} \mathrm{~g}^{-1} \mathrm{~s}^{-1}$. The obtained $k_{2}$ value was compared to that of synthetic antioxidants and natural extracts used in the food industry. Kinetic analysis of PE antiradical effectiveness showed that the $k_{2}$ was within the range values for natural colorants of fruit extracts and should be considered as a fast acting natural antioxidant source. The $k_{2}$ parameter indicates the extent of oxidation inhibition that is based on all of the kinetic profiles of DPPH bleaching rather than single point measurements. For this reason, the kinetic analysis should become a necessary step for more precise antioxidative characterization of propolis.

Keywords: antioxidative activity, kinetic analysis, proplis extract, second order rate constant

\section{INTRODUCTION}

Propolis, a natural substance collected by honeybees, is often used in the food industry as a supplement as well as in folk medicine to prevent and treat colds, wounds, ulcers, rheumatism, diabetes and dental caries (Castro et al., 2003; Jug, Končić, \& Kosalec, 2014; Neves et al., 2016; Prytzyk et al., 2003; Ristivojević et al., 2015). Several pharmacological properties of propolis, antibacterial (Dimkić et al., 2016; Ristivojević et al., 2015a; 2015b), antifungal (Dimkić et al., 2016; Ristivojević et al., 2015b;
Stepanović et al., 2003) and antioxidant (Žižić et al., 2013), are attributed to polyphenolic compounds.

The antioxidant properties of propolis are particularly important for food (Viuda-Martos et al., 2013) and biological systems (Dimkić et al., 2016), and therefore its antioxidative activity must be assessed. Among various assays employed to determine propolis antioxidative activity (Kumazawa et al., 2004; Mot et al., 2011; Potkonjak et al., 2012) spectrophotometric assays determining the capacity of free radical scavenging are predominantly used (Da 
Silva et al., 2006; Moreira et al., 2008). Free radical scavenging is generally accepted for antioxidants inhibiting lipid oxidation (Rufino et al., 2009). The antioxidative activity of propolis can be quantified through the determination of radical scavenger capacity values in 2.2-diphenyl-1-picrylhydrazyl free radical (DPPH') scavenging assay systems (Ahn et al., 2017; Gregoris \& Stevanato, 2010; Kumazawa et al., 2004; Laskar et al., 2010; Miguel et al., 2010; 2014; Moreira et al., 2008). Traditional DPPH radical scavenging capacity assay is informative for the antioxidative capacity of that sample but does not take into account the whole kinetic profile (Mot et al., 2011). The strong antioxidative activitiy of $P E$ is known from previous works (Potkonjak et al., 2012; Ristivojević et al., 2015; Žižić et al., 2013) but no kinetic characterization has been performed. In this paper we assessed the antiradical effectiveness of propolis extract (PE) using the 2.2-diphenyl-1-picrylhydrazyl radical (DPPH-) bleaching assay kinetics profile. Afterwards the kinetic analysis of PE studied herein were compared to those of synthetic, natural antioxidants and other natural extracts used in the food industry.

\section{MATERIAL AND METHODS}

\section{Chemicals}

All chemicals and reagents were of analytical grade and supplied from Sigma (St. Louis, USA) and Merck-Alkaloid (Skopje, FYR Macedonia).

\section{Propolis sample from South Serbia}

The propolis sample was collected in southern Serbia. The one representative sample was obtained through the mixing of the propolis from twelve different apiaries. The sample was kept at $0-5^{\circ} \mathrm{C}$ and in protected room light until analysis. The raw material of the propolis sample was frozen at $-20^{\circ} \mathrm{C}$ overnight and then rapidly ground in a mortar to obtain a homogeneous powder.

\section{Extract preparation}

Extract preparation of propolis was performed using $96 \%$ vol. ethanol. The grounded propolis
(2.0 g) and solvent $\left(20 \mathrm{~cm}^{3}\right)$ were put in an Erlenmeyer flask, which was placed in a thermostated water bath. The extraction was performed at the boiling temperature of the solvent $\left(T_{k}\right)$ and it lasted four hours. At the end of the procedure, the liquid extract was separated from the solid residue through vacuum filtration and stored in a freezer for subsequent analysis. The propolis extract (PE) was evaporated in a vacuum for dryness and constant weight.

\section{Characterization of the propolis extract}

The yield of extractive substances was calculated as a ratio between the amount of the prepared dry extracts and quantity of extracted raw propolis and expressed as a percentage $\%(w / w)$. The total phenolics content in the extracts was determined with a spectrophotometer according to the Folin-Ciocalteu method using Gallic acid as a standard (Kumazawa et al., 2004). Total phenolic content was expressed as Gallic acid equivalents in mg per $1 \mathrm{~g}$ of propolis extract (mg GAE g-1 of PE). The total flavonoid (TF) content was determined by $\mathrm{AlCl}_{3}$ coloration using Quercetin as a standard (Kumazawa et al., 2004). Total flavonoid content is expressed as Quercetin equivalents in mg per $1 \mathrm{~g}$ of propolis extract (mg Q g ${ }^{-1}$ of PE).

\section{DPPH' radical bleaching kinetic study}

A dry extract was dissolved in $10 \mathrm{ml}$ of methanol. Through further dissolving a series of solutions with different concentrations were obtained and used for the kinetics study. A solution of $7.9 \times 10^{-5} \mathrm{~mol}^{-\mathrm{dm}^{-3} \mathrm{DPPH}}{ }^{*}$ in methanol was prepared for each sample. The studied mixture was obtained from $1 \times 10^{-4} \mathrm{dm}^{3}$ of dissolved PE and $4 \times 10^{-3} \mathrm{dm}^{3}$ of DPPH' solution. Bleaching of DPPH' by PE was monitored at $520 \mathrm{~nm}$ for 540 s using LKB BIOCHROM ULTROSPEC II UVIVIS Spectrophotometer.

The scavenging reaction between DPPH" and PE can be written as:

$$
\left[\mathrm{DPPH}^{\bullet}\right]+[\mathrm{PE}] \rightarrow[\mathrm{DPPH}-\mathrm{H}]+\left[\mathrm{A}^{\bullet}\right]
$$

where $A^{*}$ is a new radical. The rate of reaction (1) is given with the equation: 


$$
-\frac{d\left[\mathrm{DPPH}^{\bullet}\right]}{d t}=k_{2}[\mathrm{PE}]\left[\mathrm{DPPH}^{\bullet}\right]_{t}
$$

where $t$ is the time, [DPPH'], is the radical concentration at $t_{1}$ and $k_{2}$ is the second-order rate constant.

The second-order rate constant $\left(k_{2}\right)$ was determined through the comparison of a large amount of the radical compound [DPPH'] with [PE] (Rufino et al., 2009). Under such conditions, the second-order reaction exhibits first-order characteristics $\left(k_{1}\right)$ described by the equation:

$$
-\frac{d[\mathrm{PE}]}{d t}=k_{1}[\mathrm{PE}]_{t}
$$

where $[\mathrm{PE}]$ is considered constant throughout the reaction and $k_{1}=k_{2}\left[\mathrm{DPPH}^{\circ}\right]$.

The solution of equation (3) is:

$$
[\mathrm{PE}]_{t}=[\mathrm{PE}]_{0} \mathrm{e}^{-k_{1} t}
$$

where $[P E]_{0}$ is the initial concentration of PE. The concentration of [DPPH'] was calculated by mass balance with the following equation (5):

$$
\left[\mathrm{DPPH}^{\bullet}\right]_{t}=\left[\mathrm{DPPH}^{\bullet}\right]_{0}\left([\mathrm{PE}]_{0} \mathrm{e}^{-k_{1} t}\right)
$$

The [DPPH'] concentration in the reaction medium was calculated from the linear calibration curve given by Brand-Williams, Cuvelier, \& Berset (1995):

$$
A_{520 \mathrm{~nm}}=11592 \times\left[\mathrm{DPPH}^{\bullet}\right]-4.9 \times 10^{-2}
$$

where [DPPH'] is expressed in $\mathrm{mol} \mathrm{dm}^{-3}$ and $A_{520 \mathrm{~nm}}$ is measured absorbance at $520 \mathrm{~nm}$.

The constants, $k_{1}$ and $k_{2}$ are graphically determined. The first-order rate constant $k_{1}$ was obtained from plots of DPPH" concentration dependent on time (Eq. 5) and $k_{2}$ was obtained from plots of $k_{1}$ dependent on PE concentration. The $k_{2}$ represents the rate at which a DPPH* radical can be oxidized by $1 \mathrm{~g}$ of PE.

\section{Statistical analysis}

Each experiment was performed in triplicate. Results are expressed as the mean \pm standard deviation (SD) of three analytical repetitions. Data from spectrophotometric readings of $\mathrm{DPPH}$ ' disappearance in the presence of various $P E$ were taken. The fittings of the experimen- tal data to Eq.5 were carried out in Origin v. 6.0 programs for Windows. The quality of fit was evaluated based on the coefficient of determination $\left(R^{2}\right)$ and the mean relative percentage deviation (MRPD), calculated according to the equation given by Rajković et al. (2016).

\section{RESULTS}

\section{Characterization of the propolis extract}

The total extract of the south Serbia propolis was $69.8 \pm 2.0 \%$. TP and TF were $155.7 \pm 3.5 \mathrm{mg}$ GAE $\mathrm{g}^{-1}$ of $P E$ and $68.7 \pm 1.3 \mathrm{mg} \mathrm{Q} \mathrm{g}^{-1}$ of $P E$, respectively. The values differed beyond the experimental error limits.

\section{DPPH'radical bleaching kinetic study}

Fig. 1 illustrates the exponential decrease of the ratio of current and initial DPPH' concentrations with the time of the progress of PE radical scavenge. Thereaction's progress was monitored by a color change of the solution from purple to yellow. This occurred because the release of hydrogen leads DPPH' to reduced form DPPH-H (Eq. 1) and as a result the color changed. Experimental bleaching data (Fig. 1) were successfulIy fitted by Eq. (5) and parameters of this fit, obtained by non-linear regression method, are shown in Tab. 1.

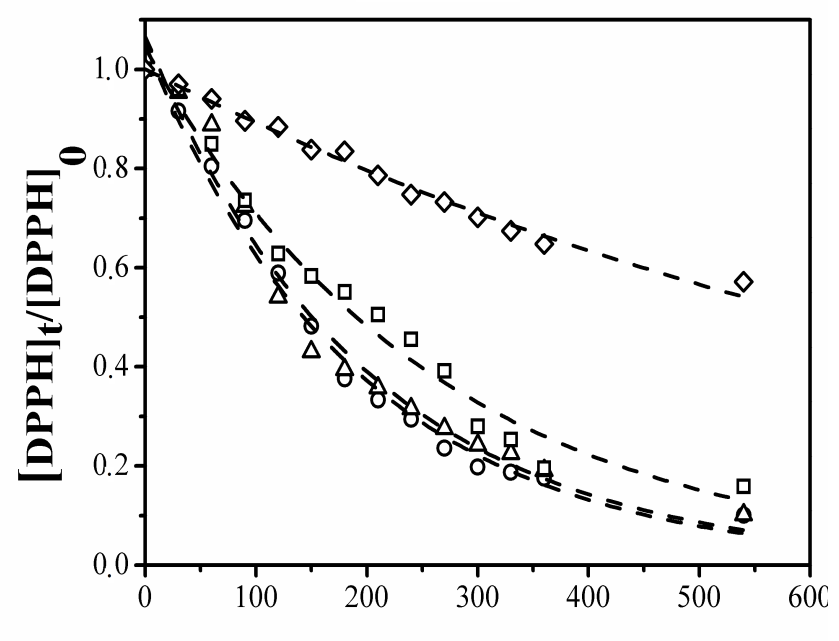

Time (s)

Fig. 1. Kinetic profiles of DPPH consumption by propolis extract for concentrations: 3.5 - $\square$; 2.6 - o; $1.8-\Delta ; \diamond-0.7 \times 10^{-2} \mathrm{~g} \mathrm{dm}^{-3}$. Lines represent fits of the experimental data according to Eq. $5\left(R^{2}=0.990\right.$ $-0.974, M R P D=1.7-6.7 \%)$. 
Table 1. Parameters of DPPH bleaching assays, shown by Eq. (5) and the second-order rate constant $\left(k_{z}\right)$

\begin{tabular}{ccccc}
\hline $\begin{array}{c}\text { Dry weight of PE } \\
\times 10^{2} \\
\left(\mathrm{~g} \mathrm{dm} \mathrm{m}^{-3}\right)\end{array}$ & $\begin{array}{c}k_{1} \times 10^{3 *} \\
\left(\mathrm{~s}^{-1}\right)\end{array}$ & $R^{2}$ & $\begin{array}{c}\text { MRPD } \\
(\%)\end{array}$ & $\begin{array}{c}k_{2}{ }^{*} \\
\left(\mathrm{dm}^{3} \mathrm{~g}^{-1} \mathrm{~s}^{-1}\right)\end{array}$ \\
\hline 3.5 & $5.2 \pm 0.2$ & 0.990 & 5.8 & \\
2.6 & $4.5 \pm 0.2$ & 0.974 & 6.7 & $0.17 \pm 0.01$ \\
1.8 & $3.8 \pm 0.1$ & 0.980 & 5.7 & \\
0.7 & $1.1 \pm 0.1$ & 0.988 & 1.7 & \\
\hline
\end{tabular}

PE- propolis extract; $k_{1}$ - the first-order kinetic rate constant; $R^{2}$ - coefficient of determination; $M R P D$ - mean relative percentage deviation.

*The mean values \pm standard deviation

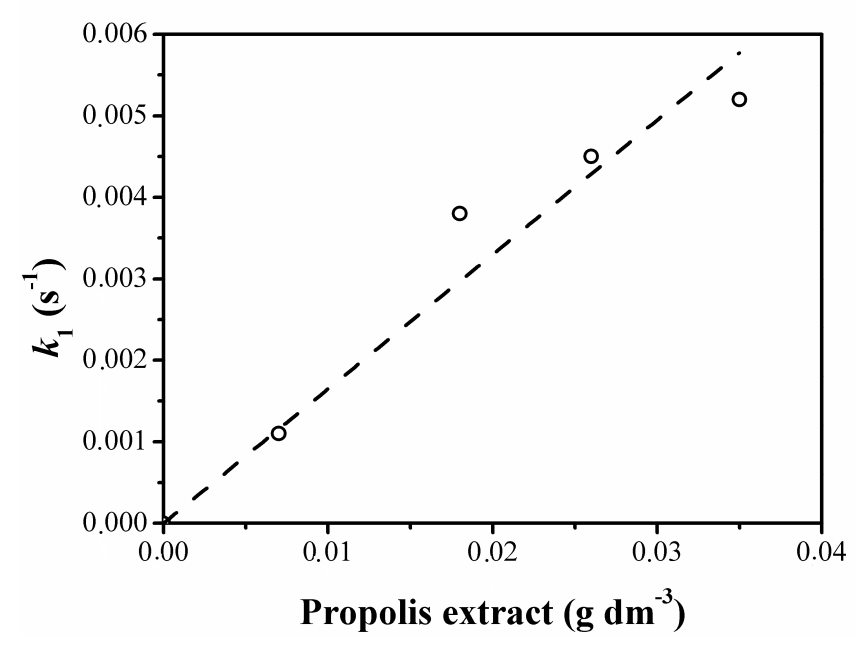

Fig. 2. The first-order rate constant $\left(k_{1}\right)$ dependent on concentration of propolis extract. Lines show linear regression fits $\left(R^{2}=0.946\right)$.

Parameters of this fit showed that the $R^{2}$-values were between 0.974 and 0.990 , while MRPDvalues were between $1.7 \%$ and $6.7 \%$ for all studied samples. $R^{2}$-values close to number one and MRPD values less than $\pm 10 \%$ point to good fit quality.

According to our results, the calculated $k_{1}$ depends on the PE as shown in Fig. 2. The $k_{2}$ value was obtained by linear regression fit of $k_{1}$ dependent on the dry weight of PE (Fig. 2). The $k_{2}$ value of PE is presented in Tab. 1.

\section{DISCUSSION}

Total phenolic and flavonoide compounds, important parameters in assessing the quality of numerous natural products, are related to their health benefits (Potkonjak et al., 2012). The variation in the TP and TF of propolis from different geographic region is mainly attributed to the difference in the preferred regional plants used by honeybees (Cottica et al., 2015; Kumazawa et al., 2004). Geographic origin cause TP and TF of PE to vary from 31 to $299 \mathrm{mg}$ GAE g-1 and from 2.5 to $176 \mathrm{mg} \mathrm{Q} \mathrm{g}^{-1}$, respectively (Kumazawa et al., 2004). Our values for TP and TF content of propolis from south Serbia were within the range of values from other geographic locations. TP of propolis from south Serbia was extremely close to the results from Brasil, South Africa, Uruguay and Uzbekistan. Our values for the TF content of propolis from south Serbia were close to the results from Ukraine. However, TP and TF content in PE from south Serbia were significantly lower than the values obtained in Australia, China and Hungary (Kumazawa et al., 2004). Besides the origin and source of the propolis, there are other limiting factors affecting the content of TP and TF of PE, such as extraction temperature and solvent (Trusheva, Trunkova, \& Bankova, 2007). The higher extraction temperature slightly improved the extraction yield (Jug, Končić, \& Kosalec, 2014), but the use of high temperatures degraded some compounds (Bakowska, 
Kucharska, \& Oszmiański, 2003). However, Trusheva, Trunkova, \& Bankova (2007) found that the percentage of total extract varies significantly with the increasing temperature, much than the amount of extracted active compounds (TP and TF). Gonzalez et al. (2009) also found that apigenin, chrysin and galangin, some of the main active flavonoids, were stable from room temperature to $120^{\circ} \mathrm{C}$.

Previous studies by Miguel et al. $(2010,2012)$ and Laskar et al. (2010) showed that solvent selection plays a major role in the content of of TP and TF in PE. Laskar et al. (2010) found that TP content in the water extract of propolis was higher than that in the ethanol extract of propolis, but it was higher in the ethanol extract. Miguel et al. (2012) found that water did not serve as a good solvent to extract TP and TF from propolis because it dissolves only a small amount of propolis constituents. Although toxic, methanol is adequate for extracting polyphenols from propolis samples, but the amounts of compounds extracted with methanol do not justify its utilization for preparing propolis extracts (Miguel et al., 2010). Therefore, ethanol is considered the first choice solvent for propolis extraction since the majority of bioactive compounds in propolis are rather lipophilic and thus soluble in ethanol (Jug, Končić, \& Kosalec, 2014) and is not as toxic as methanol. Wide variations of factors affecting the content of TP and TF of PE emphasize the need for the standardization of propolis extraction.

In this work, for the first time the PE from south Serbia was studied using a kinetics analysis based on the model of DPPH'scavenging. A fitting of bleaching data (Fig. 1) with the single-exponential decay function (Eq. (5)) showed that the kinetics profile of scavenging DPPH' of south Serbian PE exhibited one kinetic period characterized by one kinetic constant (Fig. 1). The existence of more than one kinetic period results from the presence of more than one anti-oxidant group in the sample (Mot et al., 2011). It is important to notice that in PE from south Serbia only one possible radical scavenger species is present. However, propolis from Romania has exhibited more than one kinetic period and this propolis may possess several natural radical scavenger species in their composition (Mot et al., 2011). Variation in the kinetics profile of propolis from a different geographic region is mainly attributed to differences in phenolic compounds representing radical scavenger species (Ristivojević et al., 2015a). Variability in the phenolic composition of propolis originating from a different geographical area is a direct consequence of a significant variation in their local flora, and the preferences of bees towards particular plants or plant materials (Bankova, 2009).

The $k_{2}$ of south Serbian PE was determined for the first time in this study (Tab. 1). The $k_{2}$ indicated the rate at which PE scavenges free radicals. The $k_{2}$ value of PE studied herein was compared to values determined in the same test and the same solvent of synthetic, natural antioxidants and natural extracts used in the food industry (Espin, Soler-Rivas, \& Wichers, 2000; Rufino et al., 2009). The PE showed slower antioxidant activity than $\alpha$-tocopherol $\left(1.9 \mathrm{dm}^{3} \mathrm{~g}^{-1} \mathrm{~s}^{-1}\right)$, butylated hydroxyanisole $\left(0.42 \mathrm{dm}^{3} \mathrm{~g}^{-1} \mathrm{~s}^{-1}\right)$ (Espin, Soler-Rivas, \& Wichers, 2000) and fruit extract (29.7-38.0 $\mathrm{dm}^{3} \mathrm{~g}^{-1} \mathrm{~s}^{-1}$ ) (Rufino et al., 2009) and when compared to butylated hydroxytoluene $\left(0.051 \mathrm{dm}^{3} \mathrm{~g}^{-1} \mathrm{~s}^{-1}\right)$ (Espin, Soler-Rivas, \& Wichers, 2000) was faster. The rate of PE antioxidative activity was within the range of values for natural colorants of fruit extracts $(0.0008-0.7$ $\mathrm{dm}^{3} \mathrm{~g}^{-1} \mathrm{~s}^{-1}$ ) (Espin, Soler-Rivas, \& Wichers, 2000). The $k_{2}$ value obtained in this work pointed out that PE could be just as a relevant antioxidative source as natural colorants and synthetic antioxidants (Espin, Soler-Rivas, \& Wichers, 2000).

Reports on the antioxidative activity of natural extracts have always been accompanied by a chemical characterization (Espin, Soler-Rivas, \& Wichers, 2000; Potkonjak et al., 2012; Suja, Jayalekshmy, \& Arumughan, 2004). However, the correlation between individual compound content and the antioxidative activity of Serbian propolis did not give good results (Žižić et al., 2013) due to the fact that each compound possessed different types of activity (Bankova, 2005), and synergistic effects (Boisard et al., 2015; Chen \& Shen, 2008). For these reasons, additional kinetic analyses of $P E$ 


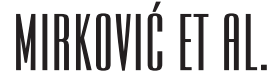

using $k_{2}$ provided new insight into antioxidative activities. The $k_{2}$ parameter indicates the extent of oxidation inhibition that is based on the entire kinetic profiles of $\mathrm{DPPH}^{*}$ bleaching rather than single point measurements. In this study only the kinetic profile of scavenging DPPH' was determined. However, other free radicals were also used for antioxidant activity assays (Miguel et al, 2010) so it would be necessary to determine the kinetic profiles of their scavenging in future research.

Previous research considered that the $k_{2}$ was related to the antioxidative capacity (Espin, Soler-Rivas, \& Wichers, 2000; Rufino et al., 2009). However, the inclusion of antioxidative capacity data raised concern. That each antioxidant method measured a different aspect of the sample chemistry and all were non-specific and subject to numerous interferences. However, kinetics analysis is relevant for understanding how pure substances or mixtures could inhibit free radical. The present study is likely to help further research in these directions.

In this paper we reported about the kinetics of free radical scavenging by propolis from south Serbia. Results obtained in this study gave new insight into the antioxidative activities of propolis from south Serbia and indicated that it should be considered as a relatively fast-acting natural antioxidant source. We suggest that kinetic analysis should become a necessary step for more precise antioxidative characterization of propolis.

\section{ACKNOWLEDGMENTS}

This work has been funded by the Ministry of Education, Science and Technological Development of the Republic of Serbia (Grant No.0l175034). We wish to thank Dunja Popović (College of Applied Studies of Technics and Technology) for useful discussions.

\section{REFERENCES}

Ahn, M. R., Kumazawa, S., Hamasaka, T., Bang, K. S., Nakayama, T. (2007). Antioxidant activity and constituents of propolis collected in various areas of China. Food Chemistry, 101, 1383-1392. http://dx.doi. org/10.1016/j.foodchem.2006.03.045

Bakowska, A., Kucharska, Z. A., \& Oszmiański, J. (2003). The effects of heating, UV irradiation, and storage on stability of the anthocyanin-polyphenol copigment complex. Food Chemistry, 87, 349-355. http://dx.doi.org/10.1016/s0308-8146(02)00429-6

Bankova, V. (2005). Chemical diversity of propolis and the problem of standardization. Journal of Ethnopharmacology, 100, 114-117. https://doi.org/10.1016/j. jep.2005.05.004

Bankova, V. (2009). Chemical diversity of propolis makes it a valuable source of new biologically active compounds. Journal of Api Product \& ApiMedical Science, 1,23-28.

Boisard, S., Le Ray. A-M., Landreau, A., Kempf, M., Cassisa, V., Flurin, C., Richomme, P. (2015). Antifungal and antibacterial metabolites from a French poplar type propolis. Evidence-Based Complementary \& Alternative Medicine. 3192, 1-10. http://dx.doi. org/10.1155/2015/319240

Brand-Williams, W., Cuvelier, M.E., \& Berset, C. (1995). Use of a free radical method to evaluate antioxidant activity. Lebensmittel-Wissenchaft \& Technologie, 28, 25-30.

Castro, M.L., Nascimento, A.M., Ikegaki, M., CostaNeto, C.M., M Alencar, S., Rosalen, P.L. (2009). Identification of a bioactive compound isolated from Brazilian propolis type 6. Bioorganic \& Medicinal Chemistry, 17, 5332-5335. https://doi.org/10.1016/j. bmc.2009.04.066

Chen, C. \& Shen, A. (2008). Synergistic antifungal activities of thymol analogues with propolis. Natural Product Communications, 3, 279-282.

Cottica, M.S., Sabik, H., Antoine, C., Fortin, J., Graveline, N., Visentainer V. J., Britten, M. (2015). Characterization of Canadian propolis fractions obtained from two-step sequential extraction. LWT - Food Science and Technology, 60, 609-614. http://dx.doi. org/10.1016/j.lwt.2014.08.045 


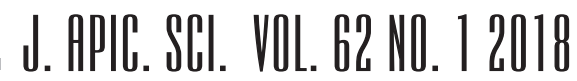

Da Silva, J.F.M., De Souza, M.C., Matta, S.R., De Andrade, M.R., Vidal, F.V.N. (2006). Correlation analysis between phenolic levels of Brazilian propolis extracts and their antimicrobial and antioxidant activities. Food Chemistry, 99, 437-435. https://doi. org/10.1016/j.foodchem.2005.07.055

Dimkić, l., Ristivojević, P., Janakiev, T., Berić, T., Trifković, J., Milojković-Opsenica, D., Stanković, S. (2016). Phenolic profiles and antimicrobial activity of various plant resins aspotential botanical sources of Serbian propolis. Industrial Crops \& Products, 94, 856-871. http://dx.doi.org/10.1016/j.indcrop.2016.09.065

Espin, J.C., Soler-Rivas, C., \& Wichers, H.J. (2000). Characterization of the total free radical scavenger capacity of vegetable oils and oil fractions using 2,2-diphenyl-7-picrylhydrazyl radical. Journal of Agricultural \& Food Chemistry, 48, 648-656. http:// dx.doi.org/10.1021/jf9908188

Gregoris, E. \& Stevanato, R. (2010). Correlations between polyphenolic composition and antioxidant activity of Venetian propolis. Food \& Chemical Toxicology, 48, 76-82. http://dx.doi.org/10.1016/j.foodchem.2008.09.098

Gonzalez, M., Gomez, M.l., Tereschuk, M.L., \& Molina, A. (2009). Thermal stability of propolis from Tucuman, Argentina. Journal of Apicultural Research and Bee World, 48(4), 270-278. http://dx.doi.org/10.3896/ IBRA.1.48.4.07

Jug, M., Končić, Z.M., \& Kosalec, I. (2014). Modulation of antioxidant, chelating and antimicrobial activity of poplar chemo-type propolis by extraction procures. LWT - Food Science \& Technology, 57, 530-537. http://dx.doi.org/10.1016/j.lwt.2014.02.006

Kumazawa, S., Hamasaka, T., \& Nakayama, T. (2004). Antioxidant activity of propolis of various geographic origins. Food Chemistry, 84, 329-339. http:// dx.doi.org/10.1016/S0308-8146 (03)00216-4

Laskar, A.R., Sk, I., Roy, N., \& Begum, A. N. (2010). Antioxidant activity of Indian propolis and its chemical constituents. Food Chemistry, 122, 233-237. http:// dx.doi.org/10.1016/j.foodchem.2010.02.068
Miguel, M.G., Nunes, S., Dandlen, S.A., Cavaco, A.M., Antunes, M.D. (2010). Phenols and antioxidant activity of hydro-alcoholic extracts of propolis from Algarve, South of Portugal. Food \& Chemical Toxicology, 48, 3418-3423. http://dx.doi.org/10.1016/j. fct.2010.09.014

Miguel, M.G., Nunes, S., Dandlen, S.A., Cavaco, A.M., Antunes, M.D. (2014). Phenols, flavonoids and antioxidant activity of aqueous and methanolic extracts of propolis (Apis mellifera L.) from Algarve, South Portugal. Food Science \& Technology, 34, 16-23. http:// dx.doi.org/10.1590/S0101-0612014000100002

Moreira, L., Dias, L.G., Pereira, J.A., \& Estevinho, L. (2008). Antioxidant properties, total phenols and pollen analysis of propolis samples from Portugal. Food \& Chemical Toxicology, 46: 3482-3485. http:// dx.doi.org/10.1016/j.fct.2008.08.025

Mot, C.A., Silaghi-Dumitrescu, R., \& Sarbu, C. (2011). Rapid and effective evaluation of the antioxidant capacity of propolis extracts using DPPH bleaching kinetic profiles, FT-IR and UV-vis spectroscopic data. Journal of Food Composition \& Analysis, 24, 516522. http://dx.doi.org/10.1016/j.fca.2010.11.006

Neves, M.V.M.D., Silva, T.M.S.D., Oliveira Lima, E.D., Cunha, E.V.L.D, Oliveira, E.D.L. (2016). Isoflavone formononetin from red propolis acts as a fungicide against Candidasp. Brazilian Journal of Microbiology, 47,159166. http://dx.doi.org/10.1016/j.bjm.2015.11.009

Potkonjak, N.I., Veselinović, D.S., Novaković, M.M., Gorjanović, S.Ž., Pezo, L.L., Sužnjević, D.Ž. (2012). Antioxidant activity of propolis extracts from Serbia: A polarographic approach. Food \& Chemical Toxicology, 50, 3614-3618. http://dx.doi.org/10.1016/j. fct.2012.07.029

Prytzyk, E., Dantas, A.P., Salomao, K., Pereira, A.S. Bankova, V.S., De Castro, S.L., Aquino Neto, F.R. (2003). Flavonoids and trypanocidal activity of Bulgarian propolis. Journal of Ethnopharmacology, 88, 189-193. http://dx.doi.org/10.1016/S0378$8741(03) 00210-1$

Rajković, K. M., Jeremić, S., Milić, P. S., Kostić, M., ArsićArsenijević, V., Gavrilović, M., Krstić, B. (2016). Opti- 
mization of Ultrasound-Assisted Extraction of Total Extractive Substances from Galium verum L. Periodica Polytechnica Chemical Engineering, 9580, 1-6. http://dx.doi.org/10.3311/PPch.9580

Ristivojević, P., Trifković, J., Andrić, F., \& MilojkovićOpsenica, D. (2015a). Poplar-type Propolis: Chemical Composition, Botanical Origin and Biological Activity. Natural Product Communications, 10, 1869-1876.

Ristivojević, P., Dimkić, I. Trifković, J., Berić, T., Vovk, l., Milojković-Opsenica, D., Stanković, S. (2015b). Antimicrobial Activity of Serbian Propolis Evaluated by Means of MIC, HPTLC, Bioautography and Chemometrics. Plos One. 17, 1-15. http://dx.doi.org/10.1371/ journal.pone.0157097

Rufino, M.S.M., Fernandes, A.N.F., Alves, E.R., \& de Brito, S.E. (2009). Free radical-scavenging behaviour of some north-east Brazilian fruits in a DPPH.system. Food Chemistry, 144, 693-695. http://dx.doi. org/10.1016/j.foodchem.2008.09.098

Stepanović, S., Antić, N., Dakić, l., \& Švabić-Vlahović, M. (2003). In vitro antimicrobial activity of propolis and synergism between propolis and antimicrobial drugs. Microbiological Research, 158, 353-357.
Suja, K.P., Jayalekshmy, A., \& Arumughan, C. (2004). Free radical scavenging behavior of antioxidant compounds of sesame (Sesamum indicum L.) in DPPH $\left(^{*}\right)$ system. Journal of Agricultural \& Food Chemistry, 52, 912-915.

Trusheva, B., Trunkova, D., \& Bankova, V. (2007). Different extraction methods of biologically active components from propolis: a preliminary study. Chemistry Central Journal, 7, 13-17. http://dx.doi. org/10.1186/1752-153X-1-13

Viuda-Martos, M., Ruiz-Navajas, Y., Fernandez-Lopez, J., \& Perez -Alvarez, J.A. (2008). Functional Properties of Honey, Propolis, and Royal Jelly. Journal of Food Science, 73, 117-124. http://dx.doi.org/10.1111/ j.1750-3841.2008.00966.x

Žižić j.B., Vuković, N.L., Jadranin, M. B., Andelković, B.D., Tešević, V.V., Kacaniov, M.M., Sukdolak, S.B., Marković, S.D. (2013). Chemical composition, cytotoxic and antioxidative activities of ethanolic extracts of propolis on HCT-116 cell line. Journal of the Science of Food \& Agriculture, 10, 1-8. http://dx.doi.org/10.1002/ jsfa.6132 